\title{
Enhanced concentrations of elements and secondary metabolites in Viola tricolor L. induced by arbuscular mycorrhizal fungi
}

\author{
Szymon Zubek • Kaja Rola • Agnieszka Szewczyk • \\ Marta L. Majewska $\cdot$ Katarzyna Turnau
}

Received: 18 August 2014 / Accepted: 14 January 2015 /Published online: 23 January 2015

(C) The Author(s) 2015. This article is published with open access at Springerlink.com

\begin{abstract}
Background and Aims Viola tricolor L. (heartsease, wild pansy) is a valuable medicinal plant obtained for pharmaceutical purposes by cultivation. Given that the species is usually strongly colonized by arbuscular mycorrhizal fungi (AMF), we tested in a pot experiment whether these microorganisms were able to influence $V$. tricolor mass, vitality, and the concentrations of selected elements, phenolic acids and flavonoids.

Methods The following treatments were prepared: (1) control: sterile soil without AMF inoculation; (2) Rhizophagus irregularis BEG144; (3) Funneliformis mosseae BEG12; and (4) both isolates. Using a combination of physiological, phytochemical and biophysical methods, we evaluated the effects of these AMF on the performance of heartsease.

Results The intensity of mycorrhizal colonization and arbuscule formation was higher when $F$. mosseae and
\end{abstract}

Responsible Editor: Thom W. Kuyper.

S. Zubek $(\triangle) \cdot$ K. Rola $\cdot$ M. L. Majewska Institute of Botany, Jagiellonian University, Kopernika 27, 31-501 Kraków, Poland e-mail: szymon.zubek@uj.edu.pl

\section{A. Szewczyk}

Department of Pharmaceutical Botany, Faculty of Pharmacy, Collegium Medicum, Jagiellonian University,

Medyczna 9, 30-688 Kraków, Poland

K. Turnau

Institute of Environmental Sciences and Małopolska Centre of

Biotechnology, Jagiellonian University,

Gronostajowa 7, 30-387 Kraków, Poland
$R$. irregularis were introduced separately than when both isolates were present. None of the AMF treatments had an impact either on $V$. tricolor vitality as expressed by photosynthetic performance index (PI) or on its shoot and root mass. However, in general, a negative correlation was found between the extent of mycorrhizal colonization and shoot mass. We found AMF species specificities in their influence on element, phenolic acid and flavonoid concentrations. Viola tricolor showed no response to $F$. mosseae. The plants inoculated with R. irregularis had higher concentrations of $\mathrm{P}, \mathrm{Zn}, \mathrm{Mg}$, and $\mathrm{Ca}$, as well as $p$-hydroxybenzoic acid and rutin, in comparison to control. Dual AMF species inoculation increased concentrations of $\mathrm{Cu}, \mathrm{Mg}$ and rutin.

Conclusions The enhanced production of secondary metabolites in $V$. tricolor shoots may be due to improved mineral nutrition by AMF and/or a result of general plant defense reaction to fungal colonization. The tendency towards biomass decrease in AMF treatments could be explained by the allocation of plant carbon both to the maintenance of symbionts and enhanced production of secondary compounds.

Keywords Arbuscular mycorrhiza (AM) · Fungal species specificity $\cdot$ Flavonoids $\cdot$ Heartsease $\cdot$ Phenolic acids $\cdot$ Wild pansy

\section{Introduction}

Over 35,000 medicinal plant species are used in medicine in different regions of the world (Kozłowski et al. 
2009). To meet the increasing demand for plants utilized in the herbal industry, recent research has emphasized the development of new techniques to improve the quality and quantity of plant material obtained from agricultural production. These techniques to enhance the biomass and standards of medicinal plants may include the proper management of indigenous arbuscular mycorrhizal fungi (AMF) and the inoculation of plants with AMF during cultivation (Gianinazzi et al. 2010; Zeng et al. 2013). AMF have been found to stimulate growth, improve resistance to pathogens, heavy metals and salinity, and influence the level of secondary metabolites in plants (Smith and Read 2008). The use of these symbiotic soil microorganisms has therefore been proposed for medicinal plant species (Ceccarelli et al. 2010; Copetta et al. 2006; Kapoor et al. 2002a, b, 2007; Khaosaad et al. 2006; Rozpądek et al. 2014; Sbrana et al. 2014; Toussaint 2007; Toussaint et al. 2007, 2008; Zubek et al. 2010, 2011, 2012a, b, c).

Viola tricolor L. (heartsease, wild pansy; Violaceae) is a common annual or biennial plant, indigenous to Eurasia (Valentine et al. 1968), with reputed medicinal value; the species is included in the European Pharmacopoeia (2014) and other pharmaceutical monographs (Wichtl 2004; Evans 2009). The shoots of $V$. tricolor contain, e.g., salicylic acid and its derivatives, other phenolic carboxylic acids, flavonoids, mucilage and tannins (Wichtl 2004). The flowering aerial parts of heartsease have been utilized to treat various skin disorders and upper respiratory problems, and have also been used as a diuretic (Senderski 2007; van Wyk and Wink 2008). In recent studies, the species was found to exhibit antioxidative activity (Vukics et al. 2008) and to exert cytotoxic effects on human cancer cell lines (Svangard et al. 2004). Formerly, for pharmaceutical purposes the plant was collected only in the wild, but to meet increasing demand for raw material for the herbal industry, the species has been cultivated through its introduction into agriculture (Senderski 2007; van Wyk and Wink 2008). Furthermore, the data in the literature indicate that V. tricolor is usually strongly colonized by AMF (Wang and Qiu 2006; Zubek and Błaszkowski 2009; Słomka et al. 2011).

Given that AMF may enhance the standard and quantity of medicinal plants, the aim of the present study was to test in a pot experiment whether these microorganisms were able to influence $V$. tricolor mass, vitality, and the concentrations of selected elements, phenolic acids and flavonoids. The effects of AMF inoculation on heartsease were evaluated using physiological and phytochemical methods, namely biomass and mycorrhizal colonization assessment, HPLC measurements of secondary metabolites, and evaluation of the concentrations of elements, as well as a biophysical method known as JIP test. This test translates the polyphasic chlorophyll $a$ fluorescence transient OJIP exhibited by plants upon illumination to the biophysical parameters of photosynthetic machinery, thereby evaluating the vitality of plants. It has been used successfully for the evaluation of the role of AMF inoculation on plants, including those of medicinal value (Jurkiewicz et al. 2010; Tsimilli-Michael and Strasser 2008; Zubek et al. 2010, 2012b). We hypothesized that $V$. tricolor mass, vitality, concentrations of elements and secondary metabolites would increase due to AMF inoculation. Moreover, given the existence of the selectivity and functional diversity in AM symbiosis (Helgason et al. 2002; Smith and Read 2008), we also expected differences in the response of heartsease to the applied inocula.

\section{Materials and methods}

\section{AMF inocula}

Inocula applied in the experiment were: (1) Rhizophagus irregularis (Błaszk., Wubet, Renker \& Buscot) C. Walker \& A. Schüßler (=Glomus irregulare Błaszk., Wubet, Renker \& Buscot) BEG144, (2) Funneliformis mosseae (T.H. Nicolson \& Gerd.) C. Walker \& A. Schüßler [=Glomus mosseae (T.H. Nicolson \& Gerd.) Gerd. \& Trappe] BEG12 and (3) an inoculum composed of both isolates. The fungi were multiplied on a sterile substratum (sand: expanded lava rock: rock phosphate $-3: 1: 50 \mathrm{~g} / \mathrm{L}$ ) using Plantago lanceolata L. as a host plant. Fresh inocula containing colonized P. lanceolata roots (more than $80 \%$ of root length; no other fungi were present in the material), extraradical mycelia, and spores (ca. 15 spores per $100 \mathrm{~g}$ ) were used in the experiment. For the control treatment, $P$. lanceolata was grown on a sterile substratum. No fungi were found in this material.

\section{Plant material}

The seeds of $V$. tricolor were obtained from the Institute of Natural Fibers and Medicinal Plants, Poznań, Poland. 
They were germinated on wet filter paper in Petri dishes at room temperature in daylight.

\section{Soil}

The garden soil utilized in the experiment was obtained from the Botanical Garden of the Jagiellonian University. This soil is used for the cultivation of many plant species, including those of medicinal value such as V. tricolor.

The soil was analyzed for $\mathrm{pH}$ in aqueous solution. The total nitrogen in soil was determined by means of the Kjeldahl method on Gerhardt apparatus (Switzerland), and the organic carbon using the Tiurin method (Mocek and Drzymała 2010). The content of organic matter was calculated by multiplying the organic carbon concentration value by 1.724 . The assessment of plantavailable phosphorus $\left(\mathrm{P}_{2} \mathrm{O}_{5}\right)$ and potassium $\left(\mathrm{K}_{2} \mathrm{O}\right)$ concentrations were done after extraction with ammonium lactate acetic acid according to Egner et al. (1960), using a spectrophotometer (Specol 11, Carl Zeiss, Germany) and flame photometer (Flapho 4, Carl Zeiss, Germany), respectively. The concentrations of calcium and magnesium cations were measured using the same flame photometer and spectrophotometer, respectively, in $1 \mathrm{~N}$ ammonium acetate. The concentrations of $\mathrm{CaO}$ and $\mathrm{MgO}$ were calculated by multiplying the values by 1.4 and 1.68, respectively (Mocek and Drzymała 2010).

The chemical properties of the soil were: $\mathrm{pH}-7.45$, $\mathrm{N}-0.19 \%, \mathrm{C}-2.44 \%, \mathrm{C} / \mathrm{N}-13.23$, organic matter $4.21 \%, \mathrm{P}_{2} \mathrm{O}_{5}-5 \mathrm{mg} 100 \mathrm{~g}^{-1}, \mathrm{~K}_{2} \mathrm{O}-12.8 \mathrm{mg} 100 \mathrm{~g}^{-1}$, $\mathrm{CaO}-610.4 \mathrm{mg} 100 \mathrm{~g}^{-1}, \mathrm{MgO}-10.9 \mathrm{mg} 100 \mathrm{~g}^{-1}$. The soil was autoclaved twice for $30 \mathrm{~min}$., with a one-week interval.

\section{Experimental design}

Week-old seedlings of $V$. tricolor were transferred into $1600-\mathrm{ml}$ pots ( $7 \mathrm{~cm}$ high, $17 \mathrm{~cm}$ in diameter) filled with $1400 \mathrm{ml}$ of autoclaved soil. Eight plants were planted per pot. The following treatments were prepared: (1) control: sterile soil without AMF inoculation; (2) R. irregularis BEG144; (3) F. mosseae BEG12; and (4) both AMF isolates. Fresh inocula (100 g/pot) were mixed with the soil. In the case of dual inoculum, $50 \mathrm{~g}$ of $R$. irregularis and $50 \mathrm{~g}$ of $F$. mosseae inocula were used. For the control treatment, $100 \mathrm{~g}$ of substratum with P. lanceolata non-mycorrhizal roots was added. In total, 20 pots were established, 5 repetitions per each treatment. The pots were kept in open Sun bags (Sigma-Aldrich) under plant-growth chamber conditions at $20 \pm 2{ }^{\circ} \mathrm{C}$ and the following light regime: 270 $280 \mu \mathrm{mol}$ PAR photons $\mathrm{m}^{-2} \mathrm{~s}^{-1}, 12 / 12 \mathrm{~h}$. The cultures were irrigated weekly with $200 \mathrm{ml}$ of distilled water per pot.

After three months of $V$. tricolor growth, when the plants were in their flowering period, chlorophyll (Chl) $a$ fluorescence measurements were conducted; then the plants were harvested. The roots and aboveground parts of $V$. tricolor were rinsed with deionized water. Onefifth of the roots in each pot were stained in order to visualize AMF mycelia for the mycorrhizal colonization assessment (see below). The shoots and remaining roots of each individual plant were dried at room temperature and used for the evaluation of biomass. They were weighed using an electronic analytical balance (Radwag, WPA 60/c/1) with a level of precision of $0.0001 \mathrm{~g}$. The plants from each individual pot were then mixed. The shoots and roots were divided into two parts, one used for the measurement of phenolic acid and flavonoid concentrations and the other for element analysis (see below). In the case of evaluation of the plants' vitality, determination of AMF colonization, and measurement of phenolic acid and flavonoid concentrations, five repetitions were obtained in each treatment $(N=5)$.

Evaluation of the plants' vitality

\section{Measurement of Chl a fluorescence transient OJIP}

Chl $a$ fluorescence transients OJIP were measured with a Handy PEA fluorimeter (Hansatech Instruments Ltd., King's Lynn, Norfolk, UK). The measurements were conducted on fully expanded leaves, still attached to the plants, which were dark-adapted for $30 \mathrm{~min}$ prior to measuring. The measurements were performed as described by Strasser et al. (2004) and TsimilliMichael and Strasser (2008). Ten measurements were performed on randomly chosen leaves of plants in each pot. The data from each individual pot were then averaged to finally obtain five repetitions per treatment.

\section{JIP test}

For each repetition sample (pot), the average OJIP fluorescence transients were analyzed according to the JIP test (Strasser et al. 2004), with "Biolyzer" software (Laboratory of Bioenergetics, University of Geneva, 
Switzerland). The parameter chosen for presentation was performance index on absorption basis $\left(\mathrm{PI}_{\mathrm{ABS}}\right)$, which evaluates overall photosynthetic performance. An analytical description of this parameter was given by Tsimilli-Michael and Strasser (2008).

\section{Determination of AMF colonization}

Roots were stained according to the Phillips and Hayman (1970) protocol with minor modifications. After staining, the roots were cut into fragments of ca. $1 \mathrm{~cm}$, then mounted on slides in glycerol:lactic acid $(1: 1, \mathrm{v}: \mathrm{v})$ and analyzed using a Nikon Eclipse $80 \mathrm{i}$ light microscope with Nomarski interference contrast optics. Mycorrhizal colonization assessment was carried out according to the Trouvelot method (Trouvelot et al. 1986). The parameters analyzed were mycorrhizal frequency $(\mathrm{F})$, relative mycorrhizal root length $(\mathrm{M})$, absolute mycorrhizal root length $(\mathrm{m})$, relative arbuscular richness (A) and absolute arbuscular richness (a).

The potential presence of other fungi in the investigated material was assessed using the staining and light microscopy methods detailed for AMF.

Extraction and measurement of phenolic acid and flavonoid concentrations

Phenolic acids and flavonoids in dry biomass $(0.5 \mathrm{~g}$ of each sample) were quantified in methanol extracts $\left(80{ }^{\circ} \mathrm{C}, 2 \mathrm{~h}\right)$ and, after hydrolysis, $2 \mathrm{M}$ aqueous $\mathrm{HCl}$ in $100^{\circ} \mathrm{C}$ for $1 \mathrm{~h}$ (Harborne 1998). RP-HPLC analysis was conducted according to Ellnain-Wojtaszek and Zgórka (1999) on a Merck Hitachi liquid chromatograph (LaChrom Elite) equipped with a DAD L-2455 detector and Purospher RP-18e $(250 \times 4 \mathrm{~mm} / 5 \mu \mathrm{m})$ column. Analyses were carried out at $25^{\circ} \mathrm{C}$, with a mobile phase consisting of A - methanol, B - methanol : $0.5 \%$ acetic acid, 1:4 $(v / v)$, gradient elution: A $(0: 100 \%)$, B (100:0\%), at a flow rate of $1 \mathrm{ml} \mathrm{min}^{-1}, \lambda=254 \mathrm{~nm}$ (phenolic acids), $\lambda=370 \mathrm{~nm}$ (flavonoids). The concentrations of 11 phenolic acids, namely cinnamic, ferulic, gallic, gentisic, $p$-coumaric, $p$-hydroxybenzoic, protocatechuic, $o$-coumaric, salicylic, syringic and vanillic, were measured. Moreover, the concentrations of two flavonoids, rutin and vitexin, were assessed. The identification of the analyzed compounds was done through comparison of the retention times of the peaks with authentic reference compounds and cochromatography with standards. Quantification was done through measurement of peak areas with reference to the standard curves derived from five concentrations ( 0.03125 to $\left.0.5 \mathrm{mg} \mathrm{ml}^{-1}\right)$. Standards were obtained from Sigma-Aldrich (cinnamic, gallic, gentisic, o-coumaric, protocatechuic, salicylic, syringic, rutin, vitexin) and Fluka ( $p$-coumaric, vanillic, ferulic, $p$-hydroxybenzoic). The analysis of phenolic acids and flavonoids in roots failed due to the small amount of the material used for analyses as well as the low concentrations (below detection levels) of these secondary metabolites.

Measurement of element concentrations in plants

The root and shoot samples were dried at $80^{\circ} \mathrm{C}$ and then ground with a Pulverisette 14 variable-speed rotor mill (Fritsch, Germany). For the analyses, $0.5 \mathrm{~g}$ of each sample was used. The samples were mineralized in a mixture of suprapure concentrated $\mathrm{HNO}_{3}$ (Merck) and suprapure $\mathrm{HClO}_{4}$ (Merck) $(4 / 1, v / v)$, using a hotplate (Foss Tecator Digestor Auto, Germany). The digestive was concentrated by evaporation to about $0.5 \mathrm{ml}$ and then diluted with deionized water $(17 \mathrm{~m} \Omega)$ to a final volume of $10 \mathrm{ml}$. Total $\mathrm{P}$ was measured with the molybdenum-vanadate method on a Hach-Lange DR 3800 apparatus. Total N was determined according to the Kjeldahl method using a Kjeltec 2300 apparatus (Foss Tecator, Denmark). The concentrations of $\mathrm{Cu}, \mathrm{Zn}, \mathrm{Fe}, \mathrm{K}, \mathrm{Na}, \mathrm{Ca}$, and $\mathrm{Mg}$ were determined using a Fast Sequential Atomic Absorption Spectrometer 280 (Varian, Australia). Accuracy was verified using reference international interlaboratory moss samples M2 (Steinnes et al. 1997).

Statistical analysis

One-way analysis of variance (ANOVA), followed by Tukey's HSD test, was performed to reveal significant differences in mycorrhizal and photosynthetic parameters, the mass of shoots and roots, and the concentrations of elements and secondary metabolites in plants across all treatments. Prior to the analysis, the distribution normality was verified using the Lilliefors test. Levene's test was performed to assess the equality of variances.

The correlations between mycorrhizal parameters and the mass of shoots and roots, photosynthetic parameters, the concentrations of elements and secondary metabolites, and the relationships between the concentrations of elements and secondary metabolites were tested with Pearson's correlation coefficients. In the case of significant correlations $(p<0.05)$, the combined 
effects of AMF colonization parameters (F, M, m, A, a), the type of AMF inoculum treatments, and dry mass of shoots, as well as the interaction between them on particular element and secondary metabolite concentrations, were analyzed in separate analyses of co-variance (ANCOVA). AMF colonization parameters and types of AMF inocula treatments were considered as fixed factors and constituted the main effects in all analyses. The mass of shoots was used as a covariate. Initially we tested all interactions between covariate and independent variables with interaction regression models to verify the assumption of homogeneity of regression slopes required by ANCOVA. In the case of significant interaction the results were appropriately interpreted. Type I sums of squares (SS) were used to calculate the $\mathrm{F}$ value and to determine the significance of AMF colonization parameters and type of treatment on the concentration of each element and secondary metabolite. The analyses were carried out using STATISTICA v10 (StatSoft).

\section{Results}

\section{AMF colonization}

The roots of all inoculated plants were colonized by AMF mycelia. No AMF mycelia were detected in the roots of the control treatment. No other fungi were found in the investigated material. There were no statistically significant differences in mycorrhizal frequency (F) and relative mycorrhizal root length $(\mathrm{M})$ between all tested inocula. In the case of absolute mycorrhizal root length (m), relative arbuscular richness (A) and absolute arbuscular richness (a), the parameter values were significantly higher in F. mosseae and $R$. irregularis treatments compared to the application of the inoculum composed of both isolates (Fig. 1).

Viola tricolor growth response and photosynthetic vitality

There were no visual differences in the condition of the plants from all treatments during the whole period of the experiment. Two months after the experiment setup, the individuals of $V$. tricolor started flowering in all treatments. There were no statistically significant differences in $V$. tricolor shoot and root dry mass between all treatments (Table 1). Nevertheless, in general, a significant negative correlation was found between the mass of shoots and mycorrhizal frequency (F), relative mycorrhizal root length $(\mathrm{M})$ and absolute mycorrhizal root length (m) (Table 2).

The applied AMF had no effect on V. tricolor photosynthetic performance as expressed in $\mathrm{PI}_{\mathrm{ABS}}$ (Fig. 2).

Element concentrations in roots and shoots

The plants inoculated with $R$. irregularis showed significantly higher concentrations of $\mathrm{P}, \mathrm{Zn}, \mathrm{Mg}$ and $\mathrm{Ca}$ in shoots and $\mathrm{P}$ in roots compared to control ones. Dual AMF species inoculation enhanced the concentration of $\mathrm{Cu}$ in whole plants and $\mathrm{Mg}$ in roots. Funneliformis mosseae did not influence element concentrations in plants (Fig. 3). In the cases of N, K, Fe and $\mathrm{Na}$, no effects of AMF inoculation were found (data not presented). The results showed a significant positive correlation between mycorrhizal parameters and the
Fig. 1 Mycorrhizal colonization (percentages; mean $\pm \mathrm{SD} ; N=5$ ) of Viola tricolor. Mycorrhizal parameters: $F$ - mycorrhizal frequency, $M$ - relative mycorrhizal root length, $m-$ absolute mycorrhizal root length, $A$ - relative arbuscular richness, $a$ - absolute arbuscular richness. Bars not connected with the same letter indicate statistically significant differences $(p<0.05)$

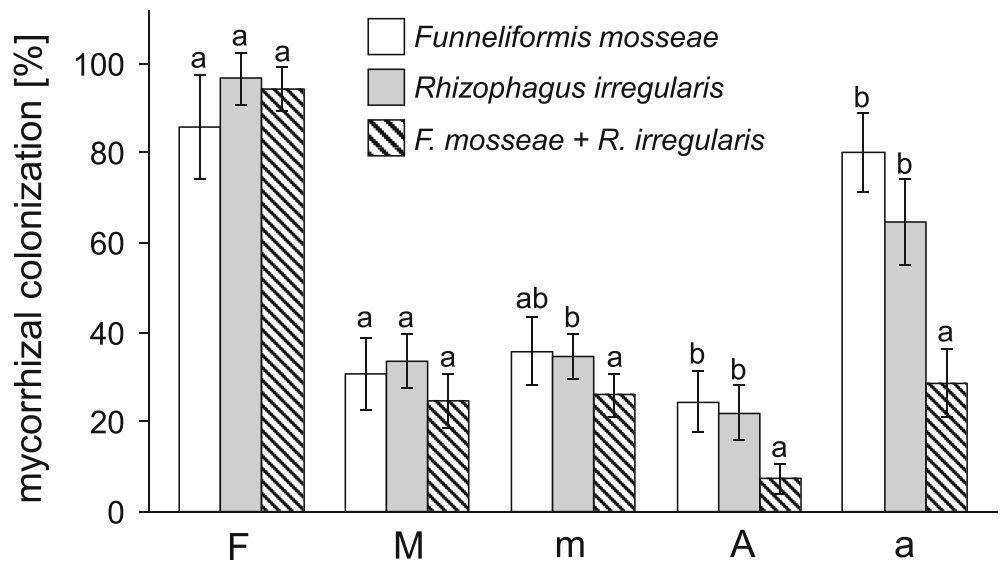


Table 1 Viola tricolor root and shoot dry mass (grams; mean \pm $\mathrm{SD} ; N=5)$

\begin{tabular}{lll}
\hline Treatment & Root mass & Shoot mass \\
\hline Control & $0.0943 \pm 0.0163$ & $0.5243 \pm 0.1515$ \\
Funneliformis mosseae & $0.0902 \pm 0.0288$ & $0.4730 \pm 0.1753$ \\
Rhizophagus irregularis & $0.0845 \pm 0.0153$ & $0.3339 \pm 0.0522$ \\
F. mosseae + R. irregularis & $0.0870 \pm 0.0170$ & $0.3545 \pm 0.0355$ \\
\hline
\end{tabular}

No statistically significant differences were found between treatments $(p>0.05)$

concentrations of $\mathrm{P}, \mathrm{Ca}, \mathrm{Cu}, \mathrm{Zn}$, and $\mathrm{Mg}$ in shoots and $\mathrm{P}$, $\mathrm{Cu}$, and $\mathrm{Mg}$ in roots (Table 2).

Phenolic acid concentrations in shoots

The plants inoculated with $R$. irregularis were characterized by a significantly higher concentration of $p$ hydroxybenzoic acid in comparison to control (Fig. 4). In the case of the 10 remaining phenolic acids, no statistically significant differences were detected between the treatments (data not shown).

A significant positive relationship between absolute mycorrhizal root length $(\mathrm{m})$ and the concentration of $p$ hydroxybenzoic acid was observed (Table 2). There was also a significant positive correlation between the concentrations of this metabolite and $\mathrm{Cu}$ in roots as well as Mg in shoots (Table 3).

Flavonoid concentrations in shoots

Viola tricolor inoculated with $R$. irregularis and dual AMF species inoculum was characterized by a significantly higher concentration of rutin in comparison to control. AMF inoculation had no effect on the concentration of vitexin (Fig. 5).

A significant positive correlation between mycorrhizal frequency $(\mathrm{F})$ and the concentration of rutin was recorded (Table 2). There was also a positive relationship between the concentrations of this metabolite and $\mathrm{P}$ and $\mathrm{Cu}$ in shoots as well as $\mathrm{Cu}$ and $\mathrm{Mg}$ in roots. As well, a significant positive correlation between the concentrations of vitexin and $\mathrm{Cu}$ in shoots was found (Table 3 ).

Effect of mycorrhizal colonization on the concentrations of elements and secondary metabolites

All AMF colonization parameters affected the concentrations of certain elements and secondary metabolites
(Table 4). In most cases we recorded the strongest impact of the presence of AMF (colonization parameters) on the model, regardless of inoculum type. The type of AMF treatment and shoot mass added little information to the model once AMF colonization parameters had been incorporated. An exception was found in the case of $\mathrm{P}$ concentration in roots, where shoot mass had an impact on the model comparable to that of mycorrhizal frequency $(F)$. Moreover, the type of AMF treatment had a significant effect on the concentrations of $\mathrm{Ca}, \mathrm{Zn}$ and $\mathrm{Mg}$ in shoots, and $\mathrm{Mg}$ in roots (Table 4).

We found no significant interactions between shoot dry mass (covariate) and independent variables in relation to the concentrations of elements. However, significant interaction of mycorrhizal frequency and shoot mass was found for rutin, thus failing to meet the assumption of ANCOVA $(F=15.70 ; p=0.011)$. This means that the effect of mycorrhizal frequency on the production of rutin varied according to plant mass. In contrast, the increase of the concentration of $p$ hydroxybenzoic acid was unrelated to the effect of plant size. ANCOVA also showed a significant effect of the interaction between mycorrhizal frequency, relative and absolute mycorrhizal root length and the type of AMF inocula on the concentration of $\mathrm{Ca}$ in shoots (Table 4). This reflects the significant increase in Ca concentration in shoots under the R. irregularis treatment (Fig. 3).

\section{Discussion}

We report here for the first time the impact of AMF on the production of phenolic acids and flavonoids in $V$. tricolor, a plant species with reputed medicinal value. This is also the first report on the influence of AMF on the concentrations of two important biologically active compounds, $p$-hydroxybenzoic acid and rutin, in plants.

We found differences in the response of heartsease to the applied fungi. Rhizophagus irregularis was more effective in the improvement of $V$. tricolor element concentrations in shoots and roots as well as in the enhancement of $p$-hydroxybenzoic acid and rutin accumulation in aerial parts. Recent investigations have revealed that various AMF species/strains may induce different changes in the production of secondary metabolites in the same plant species, or even its genotypes (Copetta et al. 2006; Kapoor et al. 2002a, b; Khaosaad et al. 2006; Larose et al. 2002; Toussaint et al. 2007; 
Table 2 Pearson's correlation coefficients between mycorrhizal parameters (F, M, m, A, a; see Materials and methods section for details) and Viola tricolor shoot mass as well as concentrations of elements, $p$-hydroxybenzoic acid and rutin

\begin{tabular}{|c|c|c|c|c|c|}
\hline \multirow[t]{2}{*}{ Variables measured } & \multicolumn{5}{|c|}{ Mycorrhizal parameters } \\
\hline & $\mathrm{F}$ & M & $\mathrm{m}$ & $\mathrm{A}$ & $\mathrm{a}$ \\
\hline Shoot mass & $-0.46^{*}$ & $-0.47^{*}$ & $-0.46^{*}$ & -0.33 & -0.28 \\
\hline \multicolumn{6}{|l|}{ Element concentration } \\
\hline P-shoot & $0.53 *$ & $0.50 *$ & $0.48 *$ & 0.37 & 0.36 \\
\hline P-root & $0.61 *$ & $0.69 * *$ & $0.72 * *$ & $0.65^{* *}$ & $0.60 *$ \\
\hline Zn-shoot & $0.57 *$ & $0.58 *$ & $0.56 *$ & $0.52 *$ & $0.51 *$ \\
\hline Mg-shoot & $0.56 *$ & $0.64 *$ & $0.58 *$ & $0.61 *$ & $0.51 *$ \\
\hline Mg-root & $0.50 *$ & $0.46^{*}$ & $0.49 *$ & 0.30 & 0.31 \\
\hline $\mathrm{Cu}$-shoot & $0.56 *$ & $0.47 *$ & 0.44 & 0.26 & 0.25 \\
\hline $\mathrm{Cu}$-root & $0.53 *$ & 0.40 & 0.42 & 0.18 & 0.23 \\
\hline Ca-shoot & $0.71 * *$ & $0.83 * *$ & $0.80 * *$ & $0.84 * *$ & $0.76 * *$ \\
\hline \multicolumn{6}{|c|}{ Secondary metabolites in shoots } \\
\hline$p$-hydroxybenzoic acid & 0.40 & 0.44 & $0.47 *$ & 0.41 & 0.37 \\
\hline rutin & $0.63 *$ & 0.44 & 0.44 & 0.23 & 0.32 \\
\hline
\end{tabular}

Significant correlations are shown in bold $(* P<0.05 ; * * P<0.001)$

Zubek et al. 2010, 2012b). For example, AMF species specificity in terms of impact on phenolic acid concentration was demonstrated in Ocimum basilicum shoots (Toussaint et al. 2007). The authors found that Funneliformis caledonium increased rosmarinic and caffeic acid production, whereas $F$. mosseae (strain NBR1-2) enhanced only the latter. Differring reactions of a host plant to inoculation with various AMF were also observed in the case of flavonoids. Larose et al.

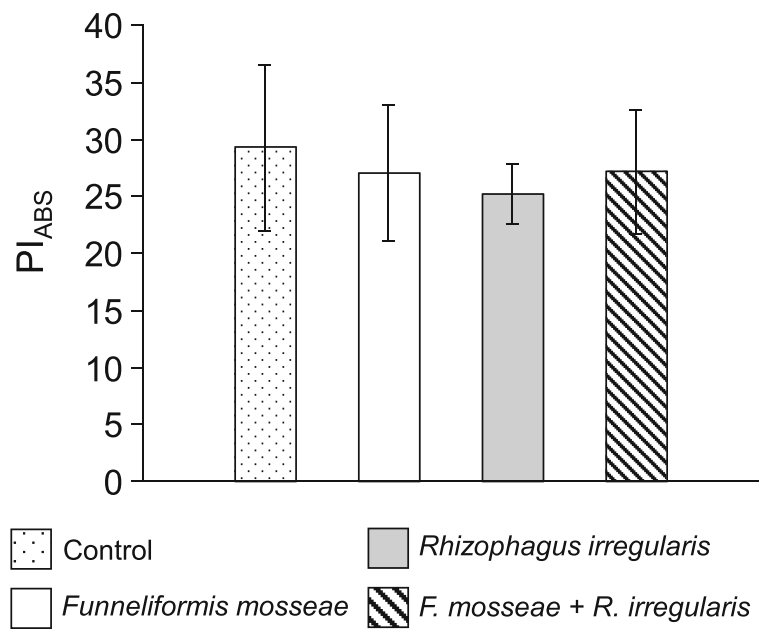

Fig. 2 Performance index $\left(\mathrm{PI}_{\mathrm{ABS}}\right.$; mean $\left.\pm \mathrm{SD} ; N=5\right)$ of Viola tricolor. No statistically significant differences were found between treatments $(p>0.05)$
(2002) found that three tested AMF, F. mosseae (BEG12), R. irregularis (DAOM197198), and Gigaspora rosea, differently influenced the production of several flavonoids in Medicago sativa roots.

Viola tricolor was nonresponsive to F. mosseae in terms of all physiological and biophysical parameters measured. In a study by Toussaint et al. (2008), no significant differences in P, caffeic and rosmarinic acid, or essential oil concentrations were found in basil shoots inoculated with F. mosseae (BEG12). However, the AM plants were characterized by higher production of rosmarinic acid in roots and increased shoot and root dry weights in comparison to the nonmycorrhizal control. Our observations are contrary to these revealed by Treseder (2013) who found that species of the Funneliformis genus, in general, are the most effective in plant mass augmentation. Moreover, in another study by Toussaint et al. (2007), even a relatively low level of colonization by F. mosseae (NBR1-2) had a considerable effect on Ocimum basilicum physiology (increased caffeic acid content in shoots).

The application of the inoculum of combined AMF species increased the concentrations of selected elements and secondary metabolites in heartsease, although the effects were not as pronounced as in the case of $R$. irregularis alone. This could be simply because of the lower intensity of mycorrhizal colonization and 

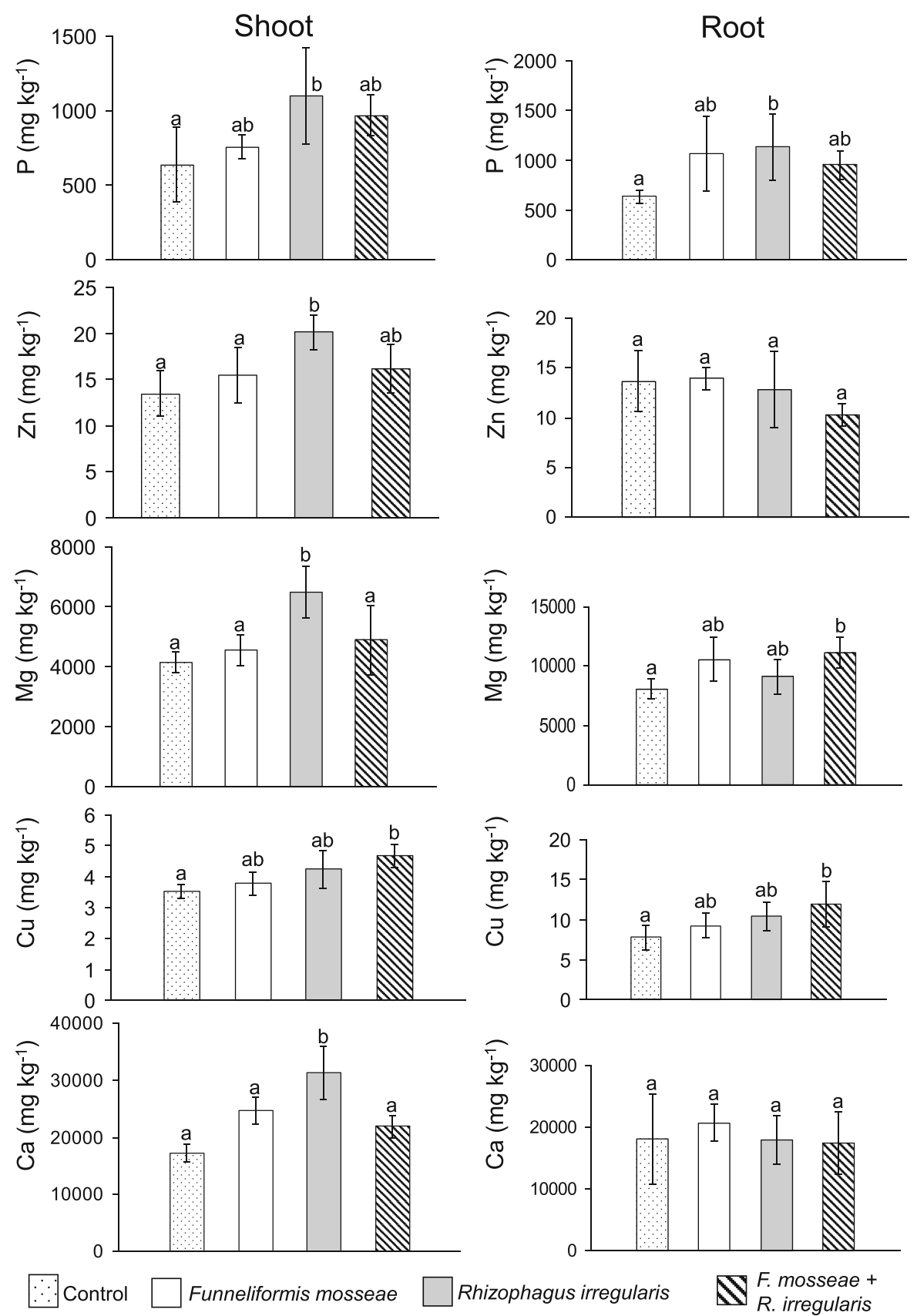

Fig. 3 Concentrations of phosphorus, zinc, magnesium, copper and calcium in Viola tricolor shoots and roots (milligrams per kilogram of dry weight; mean $\pm \mathrm{SD} ; N=5)$. Bars not connected with the same letter indicate statistically significant differences $(p<0.05)$

arbuscule formation in the case of the dual inoculation. In addition, F. mosseae might be more effective in root colonization than $R$. irregularis and thus the effect of the latter was weakened in comparison to single-species treatment. Another isolate of F. mosseae (BEG161) was found to be a rapid and dominant root colonizer compared with Rhizophagus intraradices and
Claroideoglomus claroideum used in the experiment (Jansa et al. 2008). In a study by Janoušková et al. (2009), dual inoculation with $R$. intraradices and C. claroideum did not result in any additional benefit to host plants in comparison with single inoculations. Moreover, plant growth depression caused by C. claroideum also persisted in the mixed treatment. In 


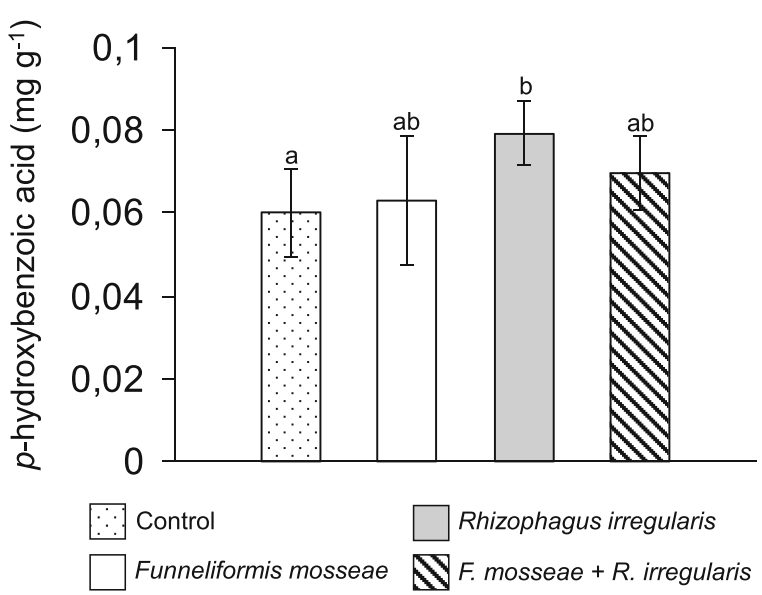

Fig. 4 Concentration of $p$-hydroxybenzoic acid in Viola tricolor shoots (milligrams per gram of dry weight; mean $\pm \mathrm{SD} ; N=5$ ). Bars not connected with the same letter indicate statistically significant differences $(p<0.05)$

contrast, Jansa et al. (2008) found that leek colonized by a mixture of $R$. intraradices and $C$. claroideum acquired more $\mathrm{P}$ than with either of the two isolates separately. Similar functional complementarity between $R$. intraradices and $F$. mosseae in the enhancement of phenolic contents of Cynara cardunculus var. scolymus was shown by Ceccarelli et al. (2010). However, we do not know the extent to which the two fungi used in our study colonized $V$. tricolor. This remains to be investigated using quantitative molecular tools.

It should be emphasized that $F$. mosseae is one of the most widespread AMF in arable soils in Europe (Oehl et al. 2003, 2004; Vestberg et al. 2005), and has also been found to be a dominant species in the agricultural systems of medicinal plants in Poland, including the areas where $V$. tricolor is cultivated (Zubek et al. 2012c, 2013). With that in mind, our observation from

Table 3 Pearson's correlation coefficients between the concentrations of elements and secondary metabolites in Viola tricolor shoots

\begin{tabular}{llll}
\hline Element concentration & \multicolumn{2}{l}{ Secondary metabolites in shoots } \\
\cline { 2 - 4 } & $p$-hydroxybenzoic acid & vitexin & rutin \\
\hline P-shoot & 0.31 & 0.37 & $\mathbf{0 . 5 5}$ \\
Mg-shoot & $\mathbf{0 . 4 7}$ & 0.24 & 0.33 \\
Mg-root & 0.12 & 0.36 & $\mathbf{0 . 5 1}$ \\
Cu-shoot & 0.45 & $\mathbf{0 . 6 2}$ & $\mathbf{0 . 6 6}$ \\
Cu-root & $\mathbf{0 . 5 8}$ & 0.23 & $\mathbf{0 . 6 6}$ \\
\hline
\end{tabular}

Significant correlations are shown in bold $(P<0.05)$
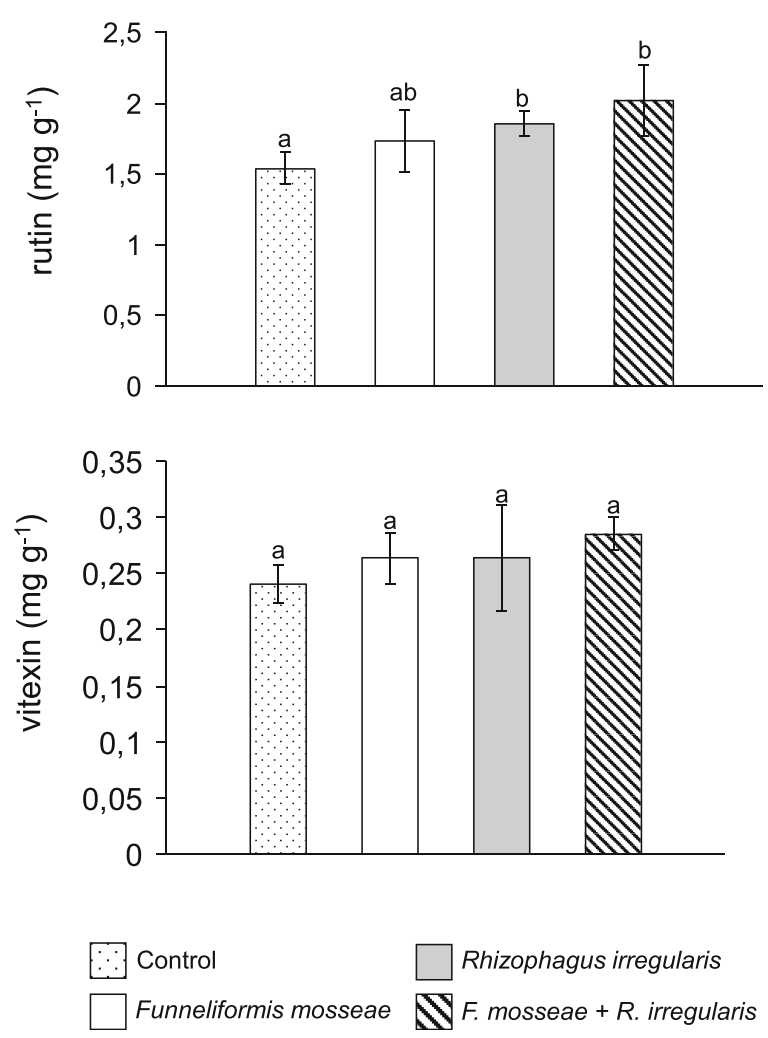

Fig. 5 Concentrations of flavonoids, rutin and vitexin, in Viola tricolor shoots (milligrams per gram of dry weight; mean $\pm \mathrm{SD}$; $N=5$ ). Bars not connected with the same letter indicate statistically significant differences $(p<0.05)$

this study suggests the need for $V$. tricolor inoculation with more effective AMF species/strains during its agricultural production.

Changes in plant secondary metabolite concentrations of AM plants may be (1) due to enhanced mineral nutrition, and/or (2) a result of plant reaction to fungal colonization (Ceccarelli et al. 2010; Copetta et al. 2006; Fontana et al. 2009; Kapoor et al. 2007; Mandal et al. 2013; Toussaint 2007; Toussaint et al. 2007; Sbrana et al. 2014). Both of these mechanisms are possible explanations for the impact of AMF on the production of phenolic acids and flavonoids in $V$. tricolor in our study.

First, significant positive correlations were found between mycorrhizal parameters and element concentrations in shoots and roots of $V$. tricolor. A likely mechanism for this relationship is increased transfer of $\mathrm{P}$ and other nutrients through more abundant mycorrhizal structures (Smith and Read 2008; Treseder 2013). Consequently, the higher nutrient availability in AM plants might have contributed to the production of both 


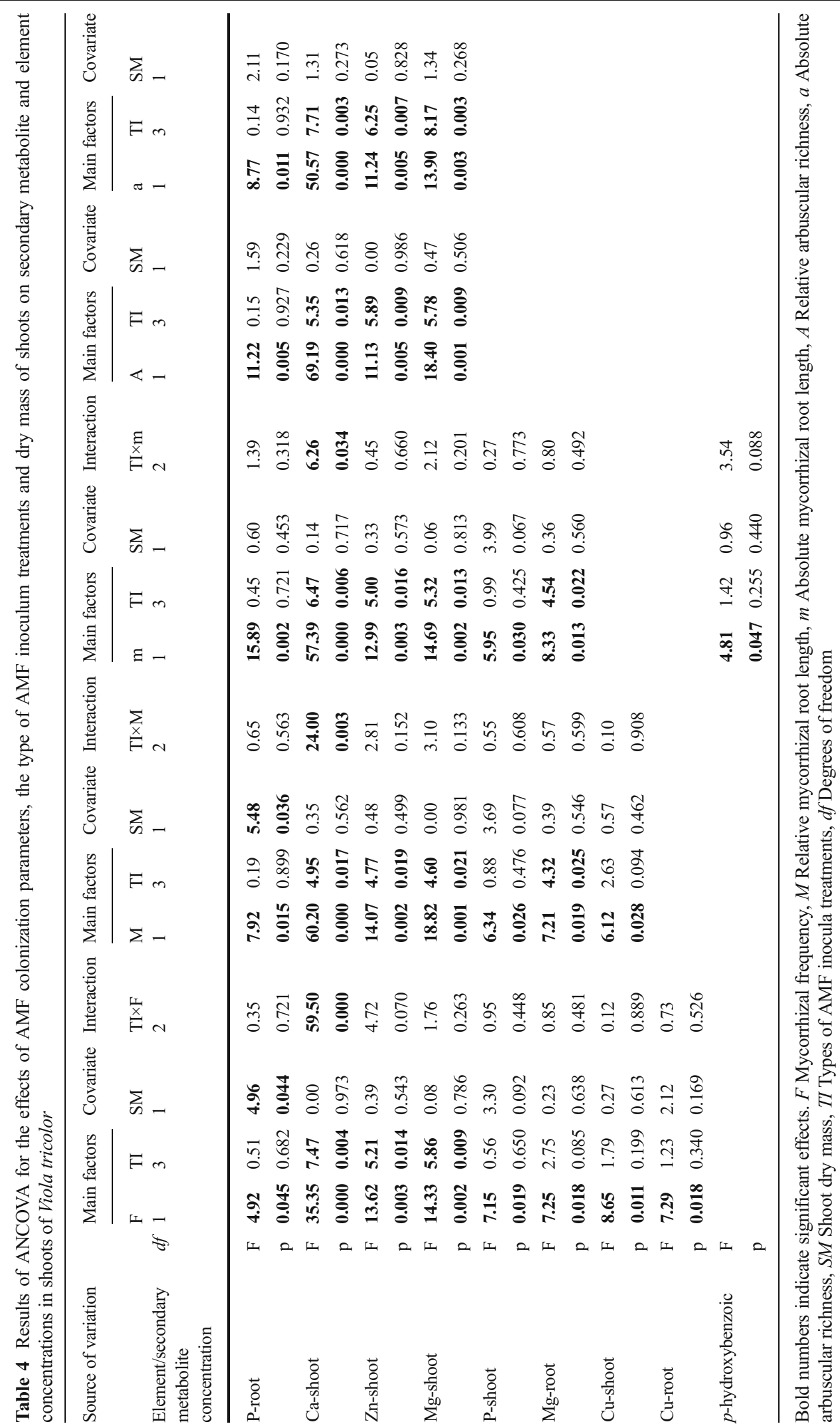


amino acids that are the precursors of phenolic compounds and enzymes involved in the synthesis of this group of chemicals (Toussaint et al. 2007). The parallel increase in element and secondary metabolite concentrations in the R. irregularis treatment, along with the absence of significant effects of $F$. mosseae, seem to support this possibility. However, in the case of better plant nutrition, we could also expect a rise in $V$. tricolor mass. Nevertheless, generally a significant negative relationship was found between the extent of mycorrhizal colonization and plant growth. Such a trend of biomass decline in mycorrhizal plants is usually explained by carbon drain for the maintenance of AM symbiosis (Smith and Read 2008). If the outflow of photosynthates to fungi is greater than the increase in productivity due to better plant nutrition, there may be a net decrease in carbon supply, leading to a decline in biomass (Fontana et al. 2009). However, in the case of limited carbon availability for plant growth, secondary metabolites should consequently not be produced in higher amounts. The parallel tendency of increased production of phenolic compounds and decrease in heartsease mass found in our study is thus difficult to explain exclusively in terms of better plant mineral nutrition mediated by AMF.

A second possible mechanism of AMF influence on plant secondary metabolism is not related to host nutritional status. The formation of AM symbiosis is characterized by chemical cross-talk mediated by changes in gene expressions and production of molecular signals both in plants and fungi. Altered gene expressions in hosts as a result of AMF colonization influence their metabolism and lead to the induction of chemical defense (Volpin et al. 1994; Fontana et al. 2009; Cameron et al. 2013). It was found that roots colonized by AMF had increased levels of transcripts encoding phenylalanine ammonia lyase (PAL) and chalcone synthase (CHS) (Blilou et al. 2000; Bonanomi et al. 2001). In the phenyl propanoid pathway, PAL is involved in the synthesis of a variety of phenolic compounds (MacDonald and D'Cunha 2007), whereas CHS is the key enzyme involved in flavonoid biosynthesis (Austin and Noel 2003). Since phenolic compounds are produced in plants as, inter alia, defense metabolites, the increased concentrations of these chemicals in $V$. tricolor in our experiment might be explained by this mechanism. In this case, the enhanced production of secondary compounds induced by $R$. irregularis and the absence of significant effects of F. mosseae, together with the similar levels of root colonization by these species, could suggest that a plant defense reaction to AMF colonization depends on fungal genotype. The tendency towards biomass decrease in AM treatments could be explained in this case by the allocation of plant carbon not only to the maintenance of the fungal symbiont but also to the enhanced production of secondary metabolites (Fontana et al. 2009).

In our study, we did not find higher concentrations of salicylic acid (SA) in the shoots of $V$. tricolor inoculated with AMF. This compound is involved in systemic signaling, mediating in plant defense against pathogens. A temporary increase in SA levels and the activation of a SA-dependent signaling pathway was found in roots in the early stages of AM development. These responses are then suppressed once the compatibility between the symbiotic partners is recognized (Garcia-Garrido and Ocampo 2002; Fontana et al. 2009; Cameron et al. 2013). Additionally, the accumulation of SA was correlated with an increase in the expression of genes encoding PAL and the accumulation of phenolic compounds in mycorrhizal roots (Blilou et al. 2000; GarciaGarrido and Ocampo 2002; Zhang et al. 2013). However, there is no evidence yet that AMF enhance the accumulation of SA in shoots (Martínez-Medina et al. 2011). The AMF treatments in our research did not also differ from control in terms of plants' vitality as expressed by photosynthetic performance index (PI). Therefore, since we harvested plants three months after AMF inoculation, the probable stress reaction of $V$. tricolor to fungal colonization, that might have been manifested in higher levels of SA and lower values of PI in mycorrhizal treatments, could not be as pronounced at this stage of plant-AMF association. Furthermore, changes in SA concentration might have occurred only in roots, activating the signaling pathways leading to the production of phenolic compounds in shoots. In order to confirm these possible mechanisms, further studies are needed. Such studies should include investigations in the levels of stress-related phytohormones and the activation of key enzymes involved in metabolic pathways leading to the production of the secondary metabolites in question at different symbiotic stages.

In our experiment, the plants in the control treatment were not provided with AMF-associated microbiota by using a filtrate of AMF inoculum. Since reports suggest that these microorganisms may influence the performance of plants (Cruz and Ishii 2011; Cruz et al. 2008; Cameron et al. 2013), the observed responses of heartsease in mycorrhizal treatments could be affected by these microbiota. 
In conclusion, AMF species specificities were observed in terms of their influence on concentrations of selected elements, phenolic acids and flavonoids in heartsease. The inoculation of $V$. tricolor with $R$. irregularis was the most effective. The application of this strain in the cultivation of heartsease can thus improve the quality of shoots harvested for pharmaceutical purposes. The enhanced production of secondary metabolites in $V$. tricolor may be due to improvement in mineral nutrition by AMF and/or a result of plant's systemic defense reaction to fungal colonization. We also found that the effect of mycorrhizal colonization frequency on the production of rutin varied according to plant mass. Smaller plants were characterized by higher concentrations of this metabolite. Further field experiments are thus needed to determine whether the yield of rutin harvested per unit of growing area would be higher for inoculated plants, which tended to be smaller in our experimental conditions, than noninoculated ones. Nevertheless, it is important for pharmaceutical purposes to produce herbal materials meeting a high standard, namely with increased contents of elements and secondary metabolites per unit mass of herbal product for direct use.

Acknowledgments Professor Katarzyna Seidler-Łożykowska (Institute of Natural Fibers and Medicinal Plants, Poznań) is acknowledged for providing us with $V$. tricolor seeds. We are also grateful for the editor and reviewers for their comments and suggestions of improvement. The present research was financially supported by the Polish Ministry of Science and Higher Education under project no. N N304 381939 (2010-2013).

Conflict of Interest The authors declare that they have no conflict of interest.

Open Access This article is distributed under the terms of the Creative Commons Attribution License which permits any use, distribution, and reproduction in any medium, provided the original author(s) and the source are credited.

\section{References}

Austin MB, Noel JP (2003) The chalcone synthase superfamily of type III polyketide synthases. Nat Prod Rep 20:79-110

Blilou I, Ocampo JA, Garcia GJ (2000) Induction of Ltp (lipid transfer protein) and Pal (phenylalanine ammonia-lyase) gene expression in rice roots colonized by the arbuscular mycorrhizal fungus Glomus mosseae. J Exp Bot 51:19691977
Bonanomi A, Oetiker JH, Guggenheim R, Boller T, Wiemken A, Vogeli LR (2001) Arbuscular mycorrhiza in minimycorrhizotrons: first contact of Medicago truncatula roots with Glomus intraradices induces chalcone synthase. New Phytol 150:573-582

Cameron DD, Neal AL, van Wees SCM, Ton J (2013) Mycorrhiza-induced resistance: more than the sum of its parts? Trends Plant Sci 18:539-545

Ceccarelli N, Curadi M, Martelloni L, Sbrana C, Picciarelli P, Giovannetti M (2010) Mycorrhizal colonization impacts on phenolic content and antioxidant properties of artichoke leaves and flower heads two years after field transplant. Plant Soil 335:311-323

Copetta A, Lingua G, Berta G (2006) Effects of three AM fungi on growth, distribution of glandular hairs, and essential oil production in Ocimum basilicum L. var. Genovese. Mycorrhiza 16:485-494

Cruz AF, Ishii T (2011) Arbuscular mycorrhizal fungal spores host bacteria that affect nutrient biodynamics and biocontrol of soilborne plant pathogens. Biol Open $1: 52-57$

Cruz AF, Horii S, Ochiai S, Yasuda A, Ishii T (2008) Isolation and analysis of bacteria associated with spores of Gigaspora margarita. J Appl Microbiol 104:1711-1717

Egner H, Riehm H, Domingo WR (1960) Untersuchungen über die chemische Bodenanalyse als Grundlage für die Beurteilung des Nährstoffzustandes der Boden. Kungl Lantbrukshögskolans Ann 26:199-215

Ellnain-Wojtaszek M, Zgórka G (1999) High-perfomance liquid chromatography and thin-layer chromatography of phenolic acids from Ginkgo biloba L. leaves collected within vegetative period. J Liq Chromatogr Relat Technol 22:1457-1471

European Pharmacopoeia, Vol 1, 8th ed. (2014) Council of Europe, Strasburg

Evans WC (2009) Trease and Evans pharmacognosy. Elsevier, Edinburgh

Fontana A, Reichelt M, Hempel S, Gershenzon J, Unsicker SB (2009) The effects of arbuscular mycorrhizal fungi on direct and indirect defense metabolites of Plantago lanceolata L. J Chem Ecol 35:833-843

Garcia-Garrido JM, Ocampo JA (2002) Regulation of the plant defence response in arbuscular mycorrhizal symbiosis. J Exp Bot 53:1377-1386

Gianinazzi S, Gollotte A, Binet M-N, van Tuinen D, Redecker D, Wipf D (2010) Agroecology: the key role of arbuscular mycorrhizas in ecosystem services. Mycorrhiza 20:519-530

Harborne JB (1998) Phytochemical methods. A guide to modern techniques of plant analysis. Chapman \& Hall, London, pp 63-64

Helgason T, Merryweather JW, Denison J, Wilson P, Young JPW, Fitter AH (2002) Selectivity and functional diversity in arbuscular mycorrhizas of co-occurring fungi and plants from a temperate deciduous woodland. J Ecol 90:371-384

Janoušková M, Seddas P, Mrnka L, van Tuinen D, Dvořáčková A, Tollot M, Gianinazzi-Pearson V, Vosátka M, Gollotte A (2009) Development and activity of Glomus intraradices as affected by co-existence with Glomus claroideum in one root system. Mycorrhiza 19:393-402

Jansa J, Smith FA, Smith SE (2008) Are there benefits of simultaneous root colonization by different arbuscular mycorrhizal fungi? New Phytol 177:779-789 
Jurkiewicz A, Ryszka P, Anielska T, Waligórski P, Białońska D, Góralska K, Tsimilli-Michael M, Turnau K (2010) Optimization of culture conditions of Arnica montana L.: effects of mycorrhizal fungi and competing plants. Mycorrhiza 20:293-306

Kapoor R, Giri B, Mukerji KG (2002a) Glomus macrocarpum: a potential bioinoculant to improve essential oil quality and concentration in Dill (Anethum graveolens L.) and Carum (Trachyspermum ammi (Linn.) Sprague). World J Microbiol Biotechnol 18:459-463

Kapoor R, Giri B, Mukerji KG (2002b) Mycorrhization of coriander (Coriandrum sativum L.) to enhance the concentration and quality of essential oil. J Sci Food Agric 82:339-342

Kapoor R, Chaudhary V, Bhatnagar AK (2007) Effects of arbuscular mycorrhiza and phosphorus application on artemisinin concentration in Artemisia annua L. Mycorrhiza 17:581-587

Khaosaad T, Vierheilig H, Nell M, Zitterl-Eglseer K, Novak J (2006) Arbuscular mycorrhiza alter the concentration of essential oils in oregano (Origanum sp., Lamiaceae). Mycorrhiza 16:443-446

Kozłowski J, Buchwald W, Forycka A, Szczygielska D (2009) Rośliny i surowce lecznicze. Instytut Włókien Naturalnych i Roślin Zielarskich, Poznań

Larose G, Chênevert R, Moutoglis P, Gagné S, Piché Y, Vierheilig H (2002) Flavonoid levels in roots of Medicago sativa are modulated by the developmental stage of the symbiosis and the root colonizing arbuscular mycorrhizal fungus. J Plant Physiol 159:1329-1339

MacDonald MJ, D'Cunha GB (2007) A modern view of phenylalanine ammonia lyase. Biochem Cell Biol 85:273-282

Mandal S, Evelin H, Giri B, Singh VP, Kapoor R (2013) Arbuscular mycorrhiza enhances the production of stevioside and rebaudioside-A in Stevia rebaudiana via nutritional and non-nutritional mechanisms. Appl Soil Ecol 72:187-194

Martínez-Medina A, Roldán A, Albacete A, Pascual JA (2011) The interaction with arbuscular mycorrhizal fungi or Trichoderma harzianum alters the shoot hormonal profile in melon plants. Phytochemistry 72:223-229

Mocek M, Drzymała S (2010) Geneza, analiza i klasyfikacja gleb. Wydawnictwo Uniwersytetu Przyrodniczego w Poznaniu, Poznań

Oehl F, Sieverding E, Ineichen K, Mäder P, Boller T, Wiemken A (2003) Impact of land use intensity on the species diversity of arbuscular mycorrhizal fungi in agroecosystems of Central Europe. Appl Environ Microbiol 69:2816-2824

Oehl F, Sieverding E, Mäder P, Dubois D, Ineichen K, Boller T, Wiemken A (2004) Impact of long-term conventional and organic farming on the diversity of arbuscular mycorrhizal fungi. Ecosyst Ecol 138:574-583

Phillips J, Hayman DS (1970) Improved procedures for clearing roots and staining parasitic and vesicular-arbuscular mycorrhizal fungi for rapid assessment of infection. Trans Br Mycol Soc 55:158-161

Rozpądek P, Wężowicz K, Stojakowska A, Malarz J, Surówka E, Sobczyk Ł, Anielska T, Ważny R, Mieszalski Z, Turnau K (2014) Mycorrhizal fungi modulate phytochemical production and antioxidant activity of Cichorium intybus L. (Asteraceae) under metal toxicity. Chemosphere 112:217-224
Sbrana C, Avio L, Giovannetti M (2014) Beneficial mycorrhizal symbionts affecting the production of health-promoting phytochemicals. Electrophoresis 35:1535-1546

Senderski ME (2007) Prawie wszystko o ziołach. M.E. Senderski, Podkowa Leśna

Słomka A, Kuta E, Szarek-Łukaszewska G, Godzik B, Kapusta P, Tylko G, Bothe H (2011) Violets of the section Melanium, their colonization by arbuscular mycorrhizal fungi and their occurrence on heavy metal heaps. J Plant Physiol 168:1191-1199

Smith SE, Read DJ (2008) Mycorrhizal symbiosis, 3rd edn. Academic, London

Steinnes E, Rühling Å, Lippo H, Mäkinen A (1997) Reference materials for large-scale metal deposition surveys. Accred Qual Assur 2:243-249

Strasser RJ, Tsimilli-Michael M, Srivastava A (2004) Analysis of the chlorophyll $a$ fluorescence transient. In: Papageorgiou GC, Govindjee (eds) Chlorophyll $a$ fluorescence: a signature of photosynthesis, vol 19, Advances in photosynthesis and respiration series (Govindjee - series editor). Kluwer Academic Publishers, Rotterdam, pp 321-362

Svangard E, Goransson U, Hocaoglu Z, Gullbo J, Larsson R, Claeson P et al (2004) Cytotoxic cyclotides from Viola tricolor. J Nat Prod 67:144-147

Toussaint JP (2007) Investigating physiological changes in the aerial parts of AM plants: what do we know and where should we be heading? Mycorrhiza 17:349-353

Toussaint JP, Smith FA, Smith SE (2007) Arbuscular mycorrhizal fungi can induce the production of phytochemicals in sweet basil irrespective of phosphorus nutrition. Mycorrhiza 17:291-297

Toussaint JP, Kraml M, Nell M, Smith FA, Smith SE, Steinkellner S, Schmiderer C, Vierheilig H, Novak J (2008) Effect of Glomus mosseae on concentration of rosmarinic and caffeic acids and essential oil compounds in basil inoculated with Fusarium oxysporum f.sp. basilica. Plant Pathol 57:1109-1116

Treseder KK (2013) The extent of mycorrhizal colonization of roots and its influence on plant growth and phosphorus content. Plant Soil 371:1-13

Trouvelot A, Kough JL, Gianinazzi-Pearson V (1986) Mesure du taux de mycorhization VA d'un systeme radiculaire. Recherche de methodes d'estimation ayant une signification fonctionnelle. In: Gianinazzi-Pearson V, Gianinazzi S (eds) Physiological and Genetical Aspects of Mycorrhizae. INRA, Paris, pp 217-221, http:/www2.dijon.inra.fr/mychintec/ Protocole/Workshop_Procedures.html

Tsimilli-Michael M, Strasser RJ (2008) In vivo assessment of plants' vitality: applications in detecting and evaluating the impact of mycorrhization on host plants. In: Varma A (ed) Mycorrhiza: state of the art, genetics and molecular biology, eco-function, biotechnology, ecophysiology, structure and systematics, 3rd edn. Springer, New York, pp 679-703

Valentine DH, Merxmüller H, Schmidt A (1968) Viola L. In: Tutin TG, Heywood VH, Burges NA, Moore DM, Valentine DH, Walters SM, Webb DA (eds) Flora europaea, vol 2. Cambridge University Press, Cambridge, pp 270-282

van Wyk BE, Wink M (2008) Medicinal plants of the world, Polish edn. Medpharm Polska, Wrocław

Vestberg M, Saari K, Kukkonen S, Hurme T (2005) Mycotrophy of crops in rotation and soil amendment with peat influence the abundance and effectiveness of indigenous arbuscular mycorrhizal fungi in field soil. Mycorrhiza 15:447-458 
Volpin H, Elland Y, Okon Y, Kapulnik Y (1994) A vesicular arbuscular mycorrhizal fungus (Glomus intraradix) induces a defence response in alfalfa roots. Plant Physiol 104:683-689

Vukics V, Kery A, Bonn GK, Guttman A (2008) Major flavonoid components of heartsease (Viola tricolor L.) and their antioxidant activities. Anal Bioanal Chem 390:1917-1925

Wang B, Qiu YL (2006) Phylogenetic distribution and evolution of mycorrhizas in land plants. Mycorrhiza 16:299-363

Wichtl M (2004) Herbal drugs and phytopharmaceuticals. Medpharm, Stuttgart, pp 646-649

Zeng Y, Guo LP, Che DB, Hao ZP, Wang JY, Huang LQ, Yang G, Cui XM, Yang L, Wu ZX, Chen ML, Zhang Y (2013) Arbuscular mycorrhizal symbiosis and active ingredients of medicinal plants: current research status and prospectives. Mycorrhiza 23:253-265

Zhang R-Q, Zhu H-H, Zhao H-Q, Yao Q (2013) Arbuscular mycorrhizal fungal inoculation increases phenolic synthesis in clover roots via hydrogen peroxide, salicylic acid and nitric oxide signaling pathways. J Plant Physiol 170:74-79

Zubek S, Błaszkowski J (2009) Medicinal plants as hosts of arbuscular mycorrhizal fungi and dark septate endophytes. Phytochem Rev 8:571-580
Zubek S, Stojakowska A, Anielska T, Turnau K (2010) Arbuscular mycorrhizal fungi alter thymol derivative contents of Inula ensifolia L. Mycorrhiza 20:497-504

Zubek S, Błaszkowski J, Mleczko P (2011) Arbuscular mycorrhizal and dark septate endophyte associations of medicinal plants. Acta Soc Bot Pol 80:285-292

Zubek S, Błaszkowski J, Buchwald W (2012a) Fungal root endophyte associations of medicinal plants. Nova Hedwigia 94: $525-540$

Zubek S, Mielcarek S, Turnau K (2012b) Hypericin and pseudohypericin concentrations of a valuable medicinal plant Hypericum perforatum L. are enhanced by arbuscular mycorrhizal fungi. Mycorrhiza 22:149-156

Zubek S, Stefanowicz AM, Błaszkowski J, Niklińska M, Seidler-Łożykowska K (2012c) Arbuscular mycorrhizal fungi and soil microbial communities under contrasting fertilization of three medicinal plants. Appl Soil Ecol 59:106-115

Zubek S, Błaszkowski J, Seidler-Łożykowska K, Bąba W, Mleczko P (2013) Arbuscular mycorrhizal fungi abundance, species richness and composition under the monocultures of five medicinal plants. Acta Sci Pol-Hortoru 12:127-141 